\title{
Los métodos de la Antropología y la Literatura
}

\author{
ReYes García del VILLAR BalóN \\ Dpto. de Ciencias Sociales y Humanidades. \\ Área de Antropología Social \\ Universidad de Córdoba
}

\section{RESUMEN}

El texto que presentamos trata de ser un acercamiento al método de la Etnoliteratura desde dos focos de interés fundamentales. Por un lado como fruto, entre otros, de la preocupación constante de la Antropología por la objetividad, tanto en su metodología y sus técnicas de investigación como en la exposición de los resultados. Por otro lado, desde lo que consideramos un planteamiento fundamental en sus unidades de análisis: la contextualización espacio-temporal del texto, la interacción autor/lector, y la retórica expresiva utilizada.

Palabras clave: Objetividad, Contexto, Retórica.

\section{SUMMARY}

The presents text tries to come up to the method of Etbnoliterature fom two focus of interest that I consider basics. On the one hand, between others, as a results of the constant preoccupation of Anthropology for objectivity, both in its methodology and techniques, as well as in the exposition of results. On the other hand, from what I consider a basic question in the units of analysis, that is, the spatial and temporal contextualization of the text, the interaction between author and reader, and the expressive rbetoric used.

Key words: Objectivity, Context, Rhetoric.

RDTP, LX, 1 (2005): 43-58 
Para mí la Etnoliteratura es un modo de conocer la condición humana, me atrevo a decir, de entender las claves más significativas de esa condición. Desde la perplejidad de una situación en la que la Ciencia del Hombre se encuentra en medio de un debate adjetival (Social y/o Cultural) y ante el peligro de que su identidad sea ocupada y sustituida por estrategias parciales (Etnografía, Trabajo de campo), la Etnoliteratura se apoya en la novela, el teatro y la poesía como urdimbre argumental en la tarea de reconducir la Antropología.

(De la Fuente Lombo 1994: 60).

El desarrollo de la antropología como modo de conocimiento del ser humano en sociedad y ciencia de la cultura, ha pasado, y sigue haciéndolo, por etapas de cambio, transformación y debate, propias del proceso como tal. Estas inflexiones para algunos autores han llegado a significar una "crisis de identidad" de la antropología, basada presuntamente en una crisis del objeto de estudio, de los métodos de investigación empleados en el trabajo de campo etnográfico, y de la representación, es decir, de la interpretación de las culturas como textos (Velasco 1997: 85-102). Cabe pensar, ante estas premisas, que lo que ha estado sobre la mesa todo este tiempo ha sido la capacidad autorial del antropólogo, tanto en el quehacer cotidiano del trabajo de campo y la interacción con el objeto de estudio, como en la escritura de los textos etnográficos y la representación/interpretación de las experiencias directas del investigador, tal como se puso de manifiesto en la reveladora duda de los años ochenta sobre la construcción objetiva del texto etnográfico y la validez, la autoridad científica del antropólogo.

La relación entre antropología y literatura la encontramos ya en los orígenes de la disciplina, si consideramos éstos en la época clásica y para muchos autores precursora de la investigación sociocultural: "Por mi parte sostengo que esta forma de saber [antropología] la diseñó mucho antes un fraile español en el siglo XVI. El fraile en cuestión fue el franciscano Bernardino de Sahagún [...], declaró que no podía cumplir su misión si ignoraba quiénes eran ellos, desconociendo su lengua y su cultura" (León Portilla 2004: 14).

Los documentos de viajeros, aventureros, funcionarios, misioneros, etc., aportaron durante aquella etapa descripciones y valoraciones de sociedades lejanas, desconocidas, "atrasadas", "exóticas", "salvajes", "simples"; escritas y recogidas, tanto con la intención de documentar rasgos y comportamientos culturales extraños y seguro perecederos, como con un interés literario o personal, e hicieron resurgir la comparación entre culturas, al mismo tiempo que un replanteamiento del significado de la otredad.

La carencia en la mayoría de los casos de fuentes documentales escri- 
tas, y el desconocimiento de las lenguas nativas, en el progresivo descubrimiento de "el otro", hacían necesario el trabajo de campo y la observación directa como instrumentos y estrategias fundamentales para su conocimiento, así como el entendimiento de la lengua nativa como la única manera de comprender una cultura. El trabajo de campo etnográfico adquiere la categoría de básico y esencial para el desarrollo de la investigación antropológica, al tiempo que la necesidad de comunicación con los nativos motiva que la lengua y el habla obtengan un significado primordial en ésta y en sus resultados.

El interés de la antropología por la lengua de una sociedad representa uno de los pilares de su desarrollo como ciencia, y ha sido estudiado desde varias perspectivas. La especificidad lingüistica de la humanidad es una premisa ampliamente aceptada entre los antropólogos, lo que supone para muchos autores entender el "lenguaje" como componente articulador de las culturas: "Conocer un lenguaje es, en cierta medida, conocer los moldes desde los que se ha configurado una determinada cultura. En este presupuesto se han basado los antropólogos para usar modelos lingüísticos en el análisis cultural" (Álvarez Munárriz 1989: 31).

La curiosidad ante lo desconocido, lo diferente, y la necesidad de comprenderlo, interpretarlo, de compartirlo, comunicarlo, traducirlo, va descubriendo una gran diversidad de sociedades, abonando el terreno al desarrollo de monografías etnográficas basadas en la observación directa de culturas diferentes, en la convivencia y la interacción con sus miembros, la participación relevante, uimparcial" y "objetiva" del etnógrafo en sus vidas cotidianas y sus manifestaciones colectivas, etc., institucionalizándose muchas de las técnicas de investigación hoy vigentes como paradigmas del trabajo del antropólogo.

De la literatura de viajeros, escritores, etc., como transmisores de la existencia de culturas diferentes y formas sociales diversas, se pasa a textos etnográficos, basados en hipótesis de trabajo y técnicas de investigación específicas, que avalan la cientificidad de la investigación.

Autores como Malinowski, Boas, Evans-Pritchard, Lévi-Strauss o Geertz, entre otros, significan para la antropología referentes particulares fundamentales, no sólo por los resultados de sus investigaciones, sino también por sus planteamientos, sus métodos de investigación y sus formas de "escritura etnográfica". La antropología lingüística estuvo interesada en sus inicios por el estudio de las lenguas habladas de aquellas culturas ágrafas estudiadas en los principios colonizadores y por la reconstrucción histórica de los pueblos a partir de sus lenguas; en la actualidad sus estudios abarcan las funciones cognitiva y comunicativa de la lengua y las implicaciones culturales del lenguaje, con el objetivo de descubrir las relaciones 
entre los "Signos" y las demás unidades culturales (relaciones sociales, nociones sobre el mundo y las cosas...) (Cardona 1989: 17).

También las transformaciones del concepto de "otredad" como objeto de estudio de las investigaciones antropológicas suscitan transformaciones en la forma de acercarnos a ésta. El desconocimiento y extrañeza manifiestos de las primeras etnografías de culturas "exóticas", "atrasadas", se transforma al centrar los antropólogos hacia mediados de la centuria pasada el objeto de su interés en la propia sociedad. El reconocimiento de la diversidad dentro de la propia sociedad hace que la antropología deba plantearse un proceso de cambio de paradigmas teóricos y metodológicos.

Estas y otras cuestiones, han llevado a nuevas búsquedas de caminos para conocer sociedades y culturas, incluida la propia, y comprender la diversidad y complejidad de los comportamientos colectivos, suponiendo la interdisciplinariedad para la práctica antropológica, un intercambio de estrategias en el acercamiento al conocimiento de los seres humanos en sociedad, haciendo uso de intereses, métodos y técnicas de trabajo adscritos a disciplinas - como la historia, la lingüística, la crítica literaria, la sociología, la geografía, la ecología, la filosofía o la psicología-, que pueden proporcionar maneras de acercarnos con otra mirada, o una mirada más completa, a la pluralidad cultural.

\section{LA CONSTRUCCIÓN DEL DISCURSO}

Han sido varios los aspectos que han preocupado al antropólogo en cuanto a la relación recíproca entre la literatura y la antropología, de los cuales nos gustaría destacar ahora los siguientes:

a. la literatura como objeto de estudio y como fuente de documentación

b. la necesidad de «literalidad» en la escritura etnográfica.

\section{La literatura como objeto de estudio y como fuente de documentación}

La literatura como fuente de documentación para el antropólogo ha representado, y sigue haciéndolo, una premisa fundamental de la investigación. Como "acción verbal" tiene que ver con las transformaciones en el objeto de estudio de la antropología y con sus métodos de investigación, desde sociedades cuyas lenguas se desconocían, hasta la actualidad en que la territorialización de la lengua no es óbice en los estudios de etnolingüística (Álvarez Munárriz 1989).

Uno de los primeros aspectos abarcados por el etnógrafo en el traba- 
jo de campo es la recogida de documentación en torno a los intereses de la investigación que pretende llevar a cabo. En este sentido, una primera fase de "toma de contacto", tiene como objetivo comenzar a ubicar, caracterizar, contextualizar el colectivo, la sociedad o elementos de ésta que sean relevantes para los objetivos de la investigación. Esta recogida de documentación por parte del investigador se extenderá, ampliará, concretará y profundizará a lo largo del trabajo de campo, ya que estos documentos requieren de una continua selección y revisión, procesualmente renovada, que, junto con la mirada reflexiva del etnógrafo, ofrecerá nueva información de interés. Tarea del investigador será valorar la relevancia de estas fuentes, tasar su calidad objetiva, interpretativa y descriptiva.

Formarán parte de este tipo de documentos, dependiendo de nuestro objeto de estudio, desde documentos oficiales/formales que ayuden a reconstruir un proceso social, hasta extractos de medios de comunicación, diarios personales, literatura de ficción, autobiografías, etc.: «el etnólogo necesita del auxilio de otras disciplinas y antes de dirigirse al campo se familiariza con la bibliografía de la región en sus diversos aspectos: geografía, historia, censos y, por supuesto, los trabajos antropológicos que puedan existir" (Jiménez 1979: 58).

Esta información puede además sugerir líneas de investigación, perspectivas diversas, información sobre lugares y grupos no disponibles para la observación directa o participante del etnógrafo. Además de esta documentación inicial y variada, el objeto de nuestra investigación puede requerir la utilización de textos específicos, y de prestación de mayor atención por su acercamiento al objeto de estudio o por su calidad objetiva o informativa.

También podemos encontrar lugares en los que la inserción del antropólogo se haga prácticamente imposible, o donde la presencia del etnógrafo, del extraño, resulte distorsionadora de la situación - como determinadas ceremonias o ritos, clubes o asociaciones, etc.- - En estos casos, el etnógrafo deberá buscar informantes desde dentro, interpretaciones de otros presentes, participantes, que puedan describir densamente las situaciones y las acciones que nos interesan.

A veces el trabajo de campo requiere que los informantes escriban sus impresiones sobre aspectos concretos de la cultura, sobre costumbres o rituales, o sobre acontecimientos pasados que sean relevantes. Esta es una de las funciones de las "historias de vida", una herramienta enriquecedora del trabajo de campo que proporciona interpretaciones, percepciones de situaciones y comportamientos, creencias y valores colectivos (Hammersley y Atkinson 2001: 175-192).

También los textos literarios pueden transmitir una experiencia, una 
interpretación de situaciones y acciones sociales. La literatura, como expresión verbal (escrita y oral), al igual que otras expresiones socioculturales como el cine, el baile, la música o la pintura, es una manifestación de los procesos de interacción que se producen en una sociedad. Estas expresiones socioculturales representan una fuente de información fundamental para los científicos sociales en general, en la medida en que transmiten y expresan - en sus formas y en sus fondos- realidades sociales, interpretaciones de la realidad, usos de ella: "la literatura, como construcción artística ficticia a través de la letra, ha creado y recreado un mundo de descripciones, arquetipos, interpretaciones, sentimientos que es parte del mundo que llamamos real, en tanto en cuanto sus construcciones de la realidad fluyen en el devenir cotidiano conjuntamente con las que elabora la ciencia, la religión, la filosofía, etc." (Del Campo 2003: 37).

La literatura escrita, la novela, la poesía o el teatro, como fuentes de información, sirven al antropólogo en la medida en que son creaciones de un actor social en un espacio y un tiempo concreto, son el resultado de un proceso y constituyen un discurso y una interpretación que el investigador deberá contextualizar y contrastar.

En muchos casos la literatura, aún asentada sobre bases del imaginario, nos ofrece información que de otro modo nos sería imposible conocer, tanto de hechos pasados, referentes históricos o míticos, como de plasmaciones de valores y costumbres, imágenes y estereotipos, referentes a una amplia gama de ámbitos sociales: "esta literatura no tiene por qué ser necesariamente leída por su valor de verdad, como representaciones ajustadas a la realidad social, sino que su valor estriba en los temas, imágenes y metáforas que aporta" (Hammersley y Atkinson, 2001: 179).

En este sentido, la misma "parcialidad" subjetiva del texto literario, puede constituir información relevante en sí misma, mostrando la perspectiva y los presupuestos del autor.

\section{La «literalidad" de la escritura etnográfica}

Como ya hemos apuntado, la idea de literatura está presente en todo el proceso de la investigación antropológica, desde los inicios, al plantearnos qué queremos estudiar y cómo articulamos un proyecto de intereses y de trabajo (objeto de estudio); más tarde, como canal de información y de comunicación/comprensión con "los otros", los nativos, sean éstos quienes sean a lo largo del trabajo de campo (método); y por último, con la comunidad científica y/o el lector común que se interese por los resultados del trabajo (representación).

La escritura etnográfica como representación de realidades sociocultu- 
rales, mantiene el interés de la antropología por la literatura, al menos desde la propuesta de Clifford Geertz de interpretar las culturas como textos: "Hacer etnografía es como tratar de leer (en el sentido de 'interpretar un texto') un manuscrito extranjero, borroso, plagado de elipsis, de incoherencias, de sospechosas enmiendas y de comentarios tendenciosos y además escrito, no en las grafías convencionales de representación sonora, sino en ejemplos volátiles de conducta modelada" (Geertz 1992: 24).

La antropología simbólica nos invita a leer las culturas, como sistemas de símbolos, en tanto se componen de fracciones de comportamientos que tienen significados para un grupo. Serán estas significaciones las que conformen una cultura, y las que deberá descubrir, traducir y transmitir el antropólogo a su cultura propia, a las posibles audiencias, mediante la etnografía.

Para Geertz, la labor del antropólogo es la de interpretar, no obtener leyes generales, sino ejemplificar las leyes generales en la diversidad cultural, en los diferentes sistemas simbólicos: "la tarea esencial en la elaboración de una teoría es, no codificar regularidades abstractas, sino hacer posible la descripción densa, no generalizar a través de casos particulares, sino generalizar dentro de éstos" (ibid.: 36).

El cuestionamiento de la autoridad del etnógrafo, de su capacidad de interpretación objetiva de una realidad cultural a través de la etnografía, será el punto de inflexión en la antropología a partir sobre todo de mediados de los años setenta, cuando se ha desarrollado la práctica y la teoría de una etnografía basada en la interpretación de la cultura como un sistema de símbolos: "la Antropología simbólica [...] tiene como objetivo fundamental la interpretación de los símbolos culturales, el conocimiento del significado profundo que tiene la cultura entendida como sistema simbólico" (Álvarez Munárriz 1989: 29).

Si la separación entre los textos de la experiencia del investigador y el texto monográfico de la investigación, radicaba en ese intento de objetividad, imparcialidad, abstracción, que requería un texto científico, Geertz defenderá hacer etnografía como la tarea del antropólogo, definiendo ésta como descripción densa: «la habilidad de los antropólogos para hacernos tomar en serio lo que dicen tiene menos que ver con su aspecto factual o su aire de elegancia conceptual, que con su capacidad para convencernos de que lo que dicen es resultado de haber podido penetrar (o, si se prefiere, haber sido penetrados por) otra forma de vida, de haber, de uno u otro modo, realmente 'estado allí'. Y en la persuasión de que este milagro ha ocurrido, es donde interviene la escritura" (Geertz 1997: 14).

Los antropólogos posmodernos, preocupados por la escritura del texto etnográfico más que por su contenido, criticarán la falta de individuos 
nativos que avalen las interpretaciones etnográficas (la visión emic), quedando la autoridad textual confundida o difuminada entre diversos autores, siendo en último caso el lector el que deberá interpretar la cultura descrita.

En este sentido, la construcción del texto etnográfico queda enmarcada en una retórica descriptiva de evocación, en la que, cada vez más, el autor incluye voces diferentes, personajes que contextualizan el discurso etnográfico.

\section{OBJETIVIDAD Y RETÓRICA}

Ambos planteamientos - la literatura como fuente de información y como recurso expresivo- giran alrededor de dos ideas clásicas y básicas para la antropología: la objetividad y la retórica expresiva del antropólogo.

El concepto de objetividad en antropología, al igual que en el resto de las ciencias sociales, no debe entenderse como absoluto, al igual que no lo es la humanidad. La objetividad en ciencias sociales, entendemos debe ser entendida más como una ambición de estrategia en el trabajo de campo, una actitud ante la metodología de la investigación, que como meta absoluta a conseguir con la investigación, con la interpretación de lo observado. Buscando esta objetividad, la metodología de investigación antropológica se lleva a cabo desde un punto de partida, una hipótesis de trabajo, unos presupuestos teóricos, y unas técnicas de investigación propias, el trabajo de campo - la observación participante, la interacción informal, las entrevistas cara a cara, dirigidas, las historias de vida,...En este sentido, el relativismo cultural y las perspectivas emic/etic, juegan un papel preponderante en la teorización del método etnográfico (Harris 2004: 29-47), y en la tarea comparativa e interpretativa del etnógrafo, convirtiéndose la empatía del investigador en una herramienta útil de participación objetiva, basada fundamentalmente en la capacidad personal del etnógrafo. En este sentido, la objetividad queda enmarcada en la subjetividad del autor. Como afirma Díaz Viana: "Una de las paradojas de la etnografía es que la 'autoridad científica' — por así decirlo- viene dada en ella por la experiencia subjetiva -ese trabajo de campo en ocasiones excesivamente mitificado" (1991: 143-160).

El método del trabajo de campo y la etnografía, siguen apareciendo como los paradigmas de la investigación antropológica, si bien ello no debe hacernos olvidar que no se puede separar al observador de lo observado. Para Harris, "la objetividad exige una explicación de la relación entre el observador que describe y los fenómenos descritos, con objeto de cumplir la norma de que los observadores especifiquen qué han he- 
cho para alcanzar el conocimiento que dicen poseer. [...] Los antropólogos con vocación científica deben incluir al observador en la descripción" (Harris 2004: 58).

Tanto en el desarrollo de la investigación como en la exposición de los resultados, inciden diversas circunstancias, desde aquellas ajenas al estudio hasta la propia situación personal del investigador. En este sentido, la formación académica, o la capacidad de empatía del etnógrafo, sus circunstancias personales o su personalidad, formarán parte del desarrollo de la investigación y también incidirán en la construcción del texto etnográfico resultante: "una etnografía no es sólo relato científico, objetivo, a través del cual las gentes y los hechos hablan por sí mismos, sino que tienen mucho que ver las circunstancias del autor y la clase y grado de relación que existieron en el campo entre investigador e investigados a la hora de la evaluación e interpretación de una etnografía" (Jiménez Núñez 1994: 32).

Si la objetividad del etnógrafo respecto a la metodología empleada en su investigación, queda avalada en el propio trabajo de campo y en "la estructuración e interdependencia de los datos y de los hechos" (Jiménez Núñez 1979: 60-61), el uso expresivo del lenguaje en la escritura etnográfica, la retórica, se basa en la necesidad del investigador de dar a conocer y hacer comprender su trabajo.

Esta idea, protagonista del debate propuesto por los llamados antropólogos posmodernos, ha supuesto uno de los ítems de la supuesta "crisis de representación" a que nos venimos refiriendo. Esta crisis de representación, basada en la capacidad del investigador para traducir otros códigos y en la aparente subjetividad literaria del etnógrafo, se pierde al asumir la necesidad del antropólogo de expresarse, de utilizar los recursos lingüísticos como herramientas descriptivas y expresivas para la interpretación: "la explicación interpretativa es, de todos modos, explicación, y no simple imaginación en libertad; lo que se necesita no es renunciar a posibles metáforas, sino revitalizar nuestros mecanismos de comprensión y nuestra sensibilidad incorporando nuevas analogías" (Reynoso 1992: 9-12).

\section{NO TANTO LO QUE HACE, COMO LO QUE LE PASA A LA GENTE}

El campo de la etnoliteratura, impulsado por el profesor De la Fuente Lombo desde el Área de Antropología Social de la Universidad de Córdoba, propone hacer antropología desde la literatura: "y este 'desde' y no 'sobre' es, [...] un hecho diferencial porque se postula precisamente a partir de la obra literaria, de la experiencia de la no apariencia, de la realidad sumergida" (De la Fuente 1997: 33). 
Preocupado por la crisis de identidad que de algún modo zarandea a la antropología durante la segunda mitad del siglo pasado, la etnoliteratura se presenta como un método de investigación complementario a la etnografía, que nos permite acercarnos a la condición humana como problema" (De la Fuente 1994: 70; 1997: 21) desde la literatura, a través de la "experiencia de la no apariencia" (De la Fuente 1997: 11-43)

La etnoliteratura como método de la antropología, está interesada en aquellas realidades de la condición humana que subyacen en la interacción social, aquello sumergido en lo expresado, lo observable, lo dicho, lo escrito. Algo que "aparece oculto", pero que es real, forma parte de la realidad, porque incide en ella y es entendida y compartida a través de la literatura. Llama De la Fuente al antropólogo etnoliterato antropólogo de biblioteca", preocupado por su estética expresiva, y dice de él: "puede ahondar en la 'trastienda' del individuo para llegar a lo 'real' desde lo 'irreal'" (De la Fuente, 1994: 60). Para De la Fuente, la antropología se ha perdido en la búsqueda de lo que la gente hace, olvidando lo que la vida deshace: "se diría que hay un interés manifiesto por descubrir lo que una sociedad ha llegado a ser, y un olvido - preocupante en mi opinión-, de lo que sus componentes han dejado de ser (el tema del paso del tiempo y la consideración de la vida del hombre como pérdida)" (ibid.: 56) En este sentido, sólo desde la intemporalidad de la literatura podemos acercarnos a aquellos elementos componentes de la condición humana, a aquello que le pasa a la gente (ibid:: 58-63).

Sin tratar de sustituir ni desvalorizar la experiencia empírica de la etnografía, desde la etnoliteratura se manifiesta la búsqueda "de una realidad no limitada por 'la realidad'; ciertamente, mientras el antropólogo/ etnógrafo —desde la descripción - hace realidad 'lo que es realidad', el escritor - desde la escritura de lo imaginario- hace realidad to que no puede ser realidad', es decir, la experiencia inasible o apenas abarcable en la observación participante, la realidad sumergida, la experiencia de la no apariencia. La Etnoliteratura construye una antropología desde la experiencia literaria" (De la Fuente 1997: 22).

El quehacer de la literatura trasciende la expresión de una experiencia real del escritor, y se transforma en la conceptualización de una idea, un pensamiento, un deseo, una fantasía personal. En este sentido, la obra literaria es una fuente de información que trata de este imaginario, que aunque individual por su autoría, es colectivo en su comprensión.

Este entendimiento entre escritor y lector requiere de un código común, de unas claves interpretativas compartidas que permitan al escritor expresarse y al lector comprender. Para De la Fuente este código es la 
condición bumana, ese entramado de interiores de los individuos y las sociedades, a su cultura endógenan (De la Fuente 1997: 35).

De este modo, los textos literarios interesan a la antropología en la medida en que se convierten en transmisores, descriptores de miradas diferentes de/sobre una realidad. Afirma el profesor Riaza (1997: 153): "al científico de la conducta humana en sociedad, al antropólogo cultural, la literatura le aporta el sentido de lo irreal, de lo fingidon.

La ficción o el imaginario como realidad ha sido motivo de estudio desde diversas disciplinas sociales como la filosofía, la teoría literaria o la antropología, entre otras, estando de acuerdo en su base en la importancia esencial del imaginario en la composición y en la creación de realidades cotidianas. Mitos, leyendas y cuentos, en su base imaginaria, funcionan como códigos colectivos reales, e inciden en comportamientos individuales y colectivos; por otro lado, hoy más que nunca podemos hablar de "irrealidades reales" y realidades virtuales, que inciden y transforman el universo de las interacciones y las identificaciones sociales.

Estas realidades cotidianas lo son en tanto en cuanto son reales para determinados agentes sociales, determinados individuos, conformando determinadas visiones o interpretaciones de "la realidad". En este sentido, trasciende un problema filosófico de fondo: la relatividad de la realidad. Esta relatividad de la realidad, queda explícita y momentáneamente escrita en un texto, en un discurso que será interpretado de diversos modos dependiendo de individuos y contextos concretos, creando nuevos discursos reales, nuevas realidades relativas.

El significado colectivo del discurso requiere del conocimiento compartido de símbolos, referentes, códigos, que den la oportunidad de comprensión y compartimiento. Un discurso, para serlo, necesita del significado colectivo, por tanto compartido. Emisor y receptor deben compartir un código, un contexto de símbolos y significados, imprescindibles para entender/traducir la esencia, la condición humana que quiere transmitirse. Por tanto, se refiere De la Fuente a un modelo cognitivo del que participan autor-lector, emisor y receptor; un modelo de realidad codificado por los interlocutores, un modelo, por tanto, cultural, subjetivo y objetivado.

\section{LA TEXTUALIZACIÓN DEL DISCURSO}

La obra literaria es generalmente personal, si bien el autor/a se nutre de información recogida de diferentes ámbitos, de sus propias experiencias, de otros autores..., y está escrita en un contexto espacio-temporal concreto y desde un cierto y específico punto de vista. Como acto de 
comunicación que es, la escritura de un texto literario tiene una determinada finalidad. El autor de un texto escribe con la intención de comunicar algo, de compartir un mensaje, un pensamiento, una idea, una experiencia, que para su completa comprensión debe ser contextualizado en el espacio-tiempo en que son creados.

La contextualización espacio-temporal como un aspecto básico para entender, interpretar, traducir, lo que el autor literario quiere transmitir, se encuentra en la base de los estudios sociolinguísticos y de crítica literaria. Conocer al autor, sus circunstancias, su vida, su entorno... su contexto, constituye un paso inicial para el análisis de los textos que éste escribe. Las condiciones sociales del autor literario, el proceso de su desarrollo como individuo, su caracterización biográfica y social, proporcionan cauces de conocimiento de sus posibles motivaciones, sus fuentes, de su intención: "puesta de manifiesto la lógica que subyace a la obra literaria, y habiéndola contrastado con la lógica de la realidad de la que el autor tomó sus materiales, podremos conocer con mayor seguridad el punto de vista del autor sobre la realidad, sus ideales, obsesiones y fobias" (Frigolé 1995: 16).

Esta intención, constituye una acción en tanto que pretende, y consigue, incidir, penetrar de alguna manera en el receptor, el lector, estableciéndose un diálogo de interpretaciones, siendo por ello una cuestión fundamental para el análisis de los textos, para hacer antropología desde los textos literarios entender cuál ha sido la intención del autor al escribirlos, qué ha tratado de transmitir. Lo que supone acercarnos al entorno espacial y temporal en que fueron creados, ya que éstos serán fruto de unas condiciones objetivas y también subjetivas, circunstancias concretas, que el antropólogo necesita contrastar: "es necesario conocer el contexto externo del que fueron extraídas las referencias, y trabajar con una perspectiva y unos conceptos adecuados para poder analizar el sistema de relaciones internas específicas de cada obra literaria" (ibid.: 17).

También para Fernández de Rota (1988: 61), ala función del contexto frente a la polisemia de la palabra es la de reducir sus posibles significados al que allí resulta el adecuado. Se eliminan del potencial semántico de la palabra, todas las acepciones excepto una que es compatible con el sentido de la frasem.

La comunicación literaria se produce entre un texto literario creado por un autor/a concreto/a, y un lector o lectora del texto en un momento $\mathrm{u}$ otro espacial y temporal.

Esta interacción - autor/lector- se produce a través del texto, en un contexto codificado de signos, símbolos y significados. El sentido (significado) del texto literario está en el discurso contextuado en que actúa, no 
tanto en el contexto original del texto como en el que son interpretados, "comprendidos", y por ello compartidos.

Caro Baroja, en sus Disquisiciones Antropológicas con Emilio Temprano, dialogando sobre mitos y leyendas como cauces de conocimiento para la Edad Antigua, responde en referencia a la narrativa concreta de cuentos y tradiciones populares: "lo que yo veo claro es que cada época, en cada circunstancia, la narración tiene un significado distinto, y hay que estudiar el contexto social en que aparece para aplicarle todo su contenido" (Caro Baroja y Temprano 1985: 114).

Para José Andrés Rojo, alo que importa, en definitiva, es la verdad que transmiten, el sentido. Ese lugar donde el lector se reconoce y se encuentra consigo mismo" (El País, Babelia 17-3-2001). De este modo, entendemos que en un análisis etnoliterario deberemos contextualizar en un espacio y un tiempo, también la "lectura" del texto literario, a los lectores mismos. Deberemos tener igualmente en cuenta el contexto espacial y temporal del lector/a, las circunstancias y motivaciones en que lee y por lo que lee determinado texto literario, qué busca y qué encuentra en éste, qué coyuntura sociocultural le rodea, cómo es su personalidad y cuál su situación, etc. En este sentido, también el grado en que el lector o la lectora conozca al autor/a, incidirá de igual modo en la lectura en sí que éste haga del texto literario.

Conocer al autor/a del texto, su biografía, su ideología o sus intenciones al escribir, pueden hacer que nos guste más o menos su obra, que la entendamos mejor, o por el contrario, que, al conocer su personalidad o motivaciones, deje de gustarnos, y al tiempo dejemos de leer su obra. Todos somos testigos de cómo un mismo texto literario leído en épocas diferentes de nuestra vida, han tenido un significado distinto, nunca el mismo. Nosotros no somos los mismos con el paso del tiempo, la acumulación de experiencias y conocimientos hace que comprendamos y demos diferentes sentidos a las cosas, a la ficción literaria.

Por otro lado, De la Fuente defiende los textos literarios como objeto de estudio de la antropología, por considerar la literatura no sólo como descriptor de una historia, sino además como "capaz a su vez de transformar y modificar las conductas de los individuos y las sociedades" (De la Fuente 1997: 33).

F. Riaza, en un intento por entender la antropología y su interés por la literatura, afirma: "La literatura no sólo transmite una idea profunda y rica sobre el ser humano sino que es creadora de humanidad. El hombre que somos cada uno de nosotros y el ideal de hombre al que tendemos procede en no escasa medida de la cantidad y calidad de literatura que hayamos incorporado a nuestra existencia. En mil formas la 
literatura es vehículo de valores y pautas de comportamiento" (Riaza 1997: 151).

En este sentido, desde la antropología son diversos los estudios realizados sobre mitos, leyendas, cuentos, etc., como transmisores de valores culturales, creencias, normas de comportamiento sociales, etc., combinación de discursos creadores de modelos que serán utilizados por los individuos y las sociedades.

Dentro de la teoría literaria contemporánea, las teorías poscoloniales y feministas, solapadas en cierto modo por los posmodernos, ejemplifican la crítica hacia "los valores y las tradiciones occidentales del pensamiento y la literatura, incluyendo versiones del posmodernismo, son culpables de un etnocentrismo represivo. Los modelos de pensamiento occidental (derivados, por ejemplo, de Aristóteles, Descartes, Kant, Marx, Nietzsche y Freud) o de la literatura (Homero, Dante, Flaubert, T.S. Eliot) han dominado el mundo de la cultura, marginalizando o excluyendo las tradiciones y las formas de vida y expresión culturales no-occidentales" (Selden, Widdowson y Brooker 2001: 268).

Determinados autores englobados en estas corrientes, como Edward Said, realizan un repaso crítico al papel jugado por la literatura en la expansión del colonialismo y el imperialismo en los siglos XIX y XX: «el poder para narrar, o para impedir que otros relatos se formen y emerjan en su lugar, es muy importante para la cultura y para el imperialismo, y constituye uno de los principales vínculos entre ambos" (Said 1996: 13), poniendo de manifiesto cómo se construyen "realidades" desde discursos ficticios amparados en las más sutiles líneas del etnocentrismo occidental.

\section{A MODO DE REFLEXIÓN}

La literatura constituye una fuente de información y conocimiento sobre determinadas y diversas experiencias y expresiones de la sociedad en que se crean los textos, del autor que los escribe. En este sentido debemos hablar de diferentes literaturas —costumbrista, realista, histórica, fantástica...- y cabe preguntarnos ¿cuántos y cuáles modos de hacer literatura interesan a la etnoliteratura?

Para De la Fuente Lombo, "no hay exclusión de géneros ni de 'territorios' en la tarea del antropólogo etnoliterato, porque desde todos ellos se apoya una concepción de la realidad, una explicación de la urdimbre de la condición humana" (De la Fuente 1997: 33).

Etnografía y literatura no se diferencian, quizá, por sus formas de escritura, sino por los objetivos del autor al escribir el texto, de lo cual dependerán los métodos que utilice en el desarrollo de su investigación, 
así como la forma expresiva e interpretativa que adopte en su discurso etnográfico o literario. En este sentido, la etnoliteratura no trata de novelar la etnografía ni de comparar etnografía y literatura, sino de buscar en los textos literarios la condición bumana, ese entramado de significaciones que homogeneizaría a los individuos, a las personas.

En este punto, la literatura como experiencia imaginaria, reflejo de la realidad, no llega a ser en sí misma más allá de la mente de cada lector. En definitiva, el lector es consciente de lo que lee, literatura o etnografía, y parte de este saber a la hora de interpretar su lectura.

De este modo, interesándonos más por la lectura del texto que por su origen mismo, en nuestro intento de comprender la condición buma$n a$, la intención y contextualización original de éste y de su autor, facilitará la interpretación de las posibles lecturas de su obra. El etnoliterato debe acercarse al texto literario tanto desde la contextualización del propio texto y de su autor, como desde las posibles lecturas del mismo. Es decir, las diferentes interpretaciones de los posibles lectores se convierten en información privilegiada en la búsqueda de la condición bumana, convirtiendo a los lectores, en informantes para el antropólogo.

En este punto nos surgen varias preguntas: ¿debemos (los antropólogos) preocuparnos sólo por nuestras lecturas de los textos literarios?, ¿debemos hacerlo (también) de las lecturas de diferentes individuos, distintos 'informantes' sobre los textos, diferentes experiencias de lecturas?. Pero si el lector que aquí nos interesa es el antropólogo, ¿cómo debe éste leer la literatura?

\section{BIBLIOGRAFÍA CITADA}

ÁlVAREZ MUNÁRRIZ, LUIS. 1989. "Lenguaje, Cultura y Cibernética", en José A. Fernández de Rota (ed.), Lengua y Cultura. Aproximación desde una semántica antropológica: 29-47. A Coruña: Ed. do Castro.

Caro Baroja, Julio y Emilio Temprano. 1985. Disquisiciones antropológicas. Madrid: Istmo.

CARDONA, G. R. 1989. "Tareas de la Etnolingüística y recolección de taxonomías populares", en José A. Fernández de Rota (ed.), Lengua y Cultura. Aproximación desde una semántica antropológica: 17-27. A Coruña: Ed. do Castro.

DE LA FUENTE LOMBO, MANUEL. 1994. "La Etnoliteratura como método antropológico", en Manuel De la Fuente (ed.), Etnoliteratura: un nuevo método de análisis en Antropología: 51-72. Córdoba: Servicio de Publicaciones de la Universidad de Córdoba.

- 1997. "La etnoliteratura en el discurso antropológico: los trabajos de la espera", en Manuel De la Fuente y $\mathrm{M}^{\mathrm{a}}$ Ángeles Hermosilla (eds.), Etnoliteratura: una antropología de ¿lo imaginario?: 11-43. Córdoba: Servicio de Publicaciones de la Universidad de Córdoba. 
Del CAMPo, A. 2003. Trovadores en la Alpujarra. Por una Antropología de la construcción burlesca de la realidad. Tesis Doctoral. Universidad de Sevilla.

DíAZ G. VIANA, LUIS. 1991a. "Antropología y Literatura: diversas formas de escritura etnográfica sobre España", en María Cátedra (ed.), Los españoles vistos por los antropólogos: 143-160. Barcelona: Júcar.

- 1991b. "Prólogo", a J. Clifford y E. Marcus (eds.), Retóricas de la antropología. Barcelona: Júcar.

FERNÁNDEZ DE ROTA, JOSÉ ANTONIO. 1988. "Antropología social y semántica", en Antropología social sin fronteras: 55-104. Madrid: Instituto de Sociología Aplicada.

- (ed.). 1989. Lengua y Cultura. Aproximación desde una semántica antropológica. A Coruña: Ed. do Castro.

FRIGOLÉ, JOAN. 1995. Un etnólogo en el teatro. Ensayo antropológico de Federico García Lorca. Barcelona: Muchnik.

GEERTZ, CLIFFORD. 1988. La interpretación de las culturas. Barcelona: Gedisa.

- 1997. El antropólogo como autor. Barcelona: Paidós.

HAMmersley, M. y P. AtKinson. 2001. Etnografía. Barcelona: Paidós.

HARRIS, MARVIN. 2004. Teorias sobre la Cultura en la Era posmoderna. Barcelona: Crítica.

JIMÉNEZ NÚÑEZ, ALFREDO. 1979. Antropología Cultural. Una aproximación a la Ciencia de la educación. Madrid: MEC.

- 1994. "Fuentes y métodos de la Antropología: consideraciones un tanto críticas", en M. De la Fuente (ed.), Etnoliteratura. Un nuevo método de análisis en Antropologia: 9-47. Córdoba: Servicio de Publicaciones de la Universidad de Córdoba.

León Portilla, Manuel. 2004. "La comprensión del otro". El País, 13-9-2004.

Pozuelo Yvancos, J. Ma . 1997. "Etnoliteratura y Semiótica de la cultura", en M. De la Fuente y $\mathrm{M}^{\mathrm{a}}$ Ángeles Hermosilla (eds.), Etnoliteratura: una antropología de ¿lo imaginario?: 123-142. Córdoba: Servicio de Publicaciones de la Universidad de Córdoba.

REYNOSO, CARLOS. 1992: "Interpretando a Clifford Geertz", en C. Geertz, La interpretación de las culturas: 9-12. Barcelona: Gedisa.

RiAZA PÉREZ, FERnANDO. 1997: "De nuevo en camino hacia el hombre", en M. De la Fuente y $\mathrm{M}^{\mathrm{a}}$ Á. Hermosilla (eds.), Etnoliteratura: una antropología de ¿lo imaginario?: 143-162. Córdoba: Servicio de Publicaciones de la Universidad de Córdoba.

SAID, EDWARD. 1996. Cultura e Imperialismo. Barcelona: Anagrama.

SELDEN, R., P. WIDDOWSON y P. BROOKER. 2001. La teoría literaria contemporánea. Barcelona: Ariel.

VelasCO, HONORIO. 1989: "Palabras y Rituales, Palabras en Rituales, Palabras Rituales", en J. A. Fernández de Rota (ed.), Lengua y Cultura. Aproximación desde una semántica antropológica: 165-185. A Coruña: Ed. do Castro.

- 1997. "La etnografía como forma de representación", en Luis Díaz G. Viana y Matilde Fernández Montes (coords.), Entre la palabra y el texto. Problemas en la interpretación de fuentes orales y escritas: 85-102. Oyartzun: Sendoa. 